\title{
CLUSTERING WILAYAH DI PROVINSI SULAWESI UTARA BERDASARKAN KARAKTERISTIK SOSIAL EKONOMI TAHUN 2017
}

\author{
Agustina Riyanti \\ Badan Pusat Statistik Kabupaten Pesawaran \\ e-mail : justafity@gmail.com
}

\begin{abstract}
Regional Medium-Term Development Plan (RPJMD) is a derivative of a medium-term national development planning system that is developed based on the potential and advantages of the area. The alleviation of poverty and unemployment as well as improving the quality of human resources through the development of competitive education and health is a strategic issue in RPJMD of Sulawesi Utara Province 20162021. Characteristics of the Sulawesi Utara Province, which consists of several islands with different regional typologies lead to the need for classification of the area so that development programs can be optimized. The social-economic indicators that is used for regional classification in Sulawesi Utara are the HDI value, percentage of the poor, economic growth, and unemployment rate. The analysis used for the identification of the areas in this research is the analysis biplot and followed by discriminant analysis. Biplot analysis is used to illustrate the diversity of variables, the proximity between objects and the relationship variables in a two-dimensional graph. Discriminant analysis is used to classify an observation into grups that are independent based on explanatory variables. The results of this study show the formation of two groups of regions. One of group consists of Manado, Bitung, Tomohon, Kotamobagu, Minahasa and Minahasa Utara. This group of regions is a district with high of HDI value, high economic growth, low poverty, and high unemployment rate.
\end{abstract}

Keyword: biplot, classification, social-economic.

Abstraksi. Rencana Pembangunan Jangka Menengah Daerah (RPJMD) merupakan turunan dari sistem perencanaan pembangunan nasional jangka menengah yang dikembangkan berdasarkan potensi dan keunggulan daerah. Penanggulangan kemiskinan dan pengangguran serta peningkatan kualitas sumber daya manusia yang berdaya saing melalui pembangunan pendidikan dan kesehatan merupakan isu strategis dalam RPJMD Provinsi Sulawesi Utara 2016-2021. Karakteristik wilayah Sulawesi Utara yang terdiri dari beberapa pulau dengan tipologi daerah yang berbeda menyebabkan perlunya klasifikasi wilayah agar program pembangunan dapat dioptimalkan. Indikator sosial ekonomi yang dipakai untuk klasifikasi wilayah di Sulawesi Utara antara lain adalah Indeks Pembangunan Manusia (IPM), persentase penduduk miskin, pertumbuhan ekonomi, dan tingkat pengangguran terbuka (TPT). Analisis yang digunakan untuk identifikasi wilayah dalam penelitian ini adalah analisis biplot dan dilanjutkan dengan analisis diskriminan. Analisis biplot digunakan untuk memberikan gambaran keragaman peubah, kedekatan antar objek dan keterkaitan peubah dalam suatu grafik dua dimensi. Analisis diskriminan digunakan untuk mengklasifikasikan suatu observasi ke dalam kelompok yang saling bebas berdasarkan sejumlah variabel penjelas. Hasil penelitian ini menunjukan terbentuknya dua kelompok wilayah. Salah satu kelompok wilayah terdiri dari Kota Manado, Kota Bitung, Kota Tomohon, Kota Kotamubagu,Kabupaten Minahasa, dan Kabupaten Minahasa Utara. Kelompok wilayah ini merupakan kabupaten/ kota dengan kriteria nilai IPM dan pertumbuhan ekonomi yang tinggi, serta persentase penduduk miskin rendah serta tingkat pengangguran terbuka yang tinggi.

Kata kunci: biplot, pengelompokan,sosial-ekonomi. 


\section{PENDAHULUAN}

Rencana Pembangunan Jangka Menengah Daerah (RPJMD) merupakan turunan dari sistem perencanaan pembangunan nasional jangka menengah yang dikembangkan berdasarkan potensi dan keunggulan daerah. Penanggulangan kemiskinan dan pengangguran serta peningkatan kualitas sumber daya manusia yang berdaya saing melalui pembangunan pendidikan dan kesehatan merupakan isu strategis dalam RPJMD Provinsi Sulawesi Utara 2016-2021.

Penanggulangan kemiskinan dan pengangguran serta peningkatan sumber daya manusia merupakan isu strategis RPJMD Pemerintah Provinsi Sulawesi Utara. Pemerintah Sulawesi Utara selalu berupaya untuk mengurangi kemiskinan di wilayahnya. Upaya penanggulangan kemiskinan yang dilakukan oleh pemerintah tergolong berhasil. Hal ini terlihat dari persentase kemiskinan Provinsi Sulawesi Utara pada Tahun 2017 sebesar 8,10 (BPS, 2018). Persentase tersebut merupakan persentase penduduk miskin terendah di gugusan Pulau Sulawesi.

Capaian peningkatan sumber daya manusia tercermin pada nilai Indek Pembangunan Manusia (IPM). Pada tahun 2017, nilai IPM Provinsi Sulawesi Utara sebesar 71,66, merupakan IPM tertinggi di gugusan Pulau Sulawesi (BPS, 2018).

Keberhasilan peningkatan sumber daya manusia dan penanggulangan kemiskinan di Sulawesi Utara tidak diikuti dengan membaiknya persoalan terkait pengangguran. Tingkat pengangguran terbuka (TPT) pada Bulan Agustus 2017 sebesar 7,18. Angka tersebut mengalami kenaikan jika dibandingkan dengan tahun sebelumnya. Pada tahun 2016, TPT Provinsi Sulawesi Utara adalah sebesar 6,18.

Sistem perencanaan pembangunan nasional yang dikembangkan berdasarkan potensi keunggulan daerah, menuntut pemerintah untuk dapat membuat perencanaan yang tepat sasaran, sehingga target pembangunan nasional dapat tercapai secara optimal. Karakteristik wilayah Propinsi Sulawesi Utara yang terdiri dari daratan utama di Pulau Sulawesi dan beberapa gugusan pulau, dengan tipologi daerah yang berbeda menyebabkan perlunya klasifikasi wilayah agar program pembangunan dapat dioptimalkan. Salah satu metode statistika yang dapat digunakan untuk pengelompokan adalah analisis biplot.

Penelitian terkait dengan pengelompokan wilayah telah banyak dilakukan. Putri dan Fithriasari (2015) melakukan pengelompokan kabupaten/ kota di Jawa Timur berdasarkan indikator kesehatan. Variabel penelitian yang digunakan merupakan variabel pembentuk indikator kesehatan, yang meliputi variabel ekonomi, pendidikan, dan epidemiologi yaitu PDRB perkapita, angka harapan hidup, angka melek huruf, rata-rata total lama sekolah penduduk usia 15 tahun, prevalensi TBC, dan prevalensi malaria. Purwandari dan Hidayat (2016) melakukan pengelompokan kabupaten dan kota di Jawa Barat menggunakan analisis biplot. Indikator yang digunakan dalam penelitian tersebut adalah angka harapan hidup saat lahir, rata-rata lama sekolah, 
angka harapan lama sekolah, dan pengeluaran per kapita..

Rukini (2017) melakukan analisis perubahan kelompok berdasarkan indikator kesejahteraan rakyat tahun 2010-2015 di Provinsi Jawa Tengah menghasilkan kesimpulan bahwa dalam kurun enam tahun telah terjadi perubahan karakteristik kabupaten/ kota yang terlihat pada perubahan posisi antar kabupaten/ kota, kuadran ataupun perubahan kelompok kabupaten/ kota berdasarkan indikator kesejahteraan rakyat 2010- 2015. Indikator yang digunakan dalam analisis tersebut adalah persentase penduduk miskin, angka harapan hidup, rata-rata lama sekolah, tingkat pengangguran terbuka, dan gini rasio. Soemartini dan Supartini (2017) melakukan pengelompokan kabupaten/ kota di Jawa Barat berdasarkan indikator masyarakat dengan menggunakan analisis K-Means. Indikator yang digunakan dalam penelitian ini adalah kepadatan penduduk, angkatan kerja, laju pertumbuhan penduduk, rata-rata pengeluaran perkapita, angka harapan hidup, dan rata-rata lama sekolah.

Wilayah kabupaten/ kota di Provinsi Sulawesi Utara memilki karakteristik yang berbeda. Pengoptimalan sistem perencanaan pembangunan berdasarkan potensi daerah menuntut diperlukannya perencanaan yang optimal dan tepat sasaran. penelitian ini bertujuan untuk mengelompokan posisi relatif setiap kabupaten/ kota di Provinsi Sulawesi Utara berdasarkan keterkaitan dengan indikator sosial ekonomi sehingga program pembangunan antar kabupaten/ kota dapat dioptimalkan. Metode statistika yang digunakan adalah analisis biplot dilanjutkan dengan analisis diskriminan untuk mengetahui ketepatan klasifikasi wilayah. Indikator yang digunakan dalam penelitian ini adalah persentase kemiskinan, pertumbuhan ekonomi, IPM, dan tingkat pengangguran terbuka. Pengelompokan kabupaten/ kota di Provinsi Sulawesi Utara diharapkan dapat menunjang perencenaan pembangunan daerah yang dikembangkan berdasarkan potensi dan keunggulan daerah.

\section{METODE PENELITIAN}

\section{Sumber Data dan Variabel Penelitian}

Data yang digunakan dalam penelitian ini adalah data sekunder yang berasal dari publikasi Badan Pusat Statistik. Unit observasi yang digunakan adalah 15 kabupaten/ kota di Provinsi Sulawesi Utara Tahun 2017. Variabel yang digunakan dalam penelitian ini adalah sebagai berikut:

Tabel 1. Variabel Penelitian

\begin{tabular}{cl}
\hline Variabel & \multicolumn{1}{c}{ Nama Variabel } \\
\hline X1 & Persentase Kemiskinan \\
X2 & Pertumbuhan Ekonomi \\
X3 & Indeks Pembangunan Manusia (IPM) \\
X4 & Tingkat Pengangguran Terbuka (TPT)
\end{tabular}




\section{Analisis Biplot}

Analisis biplot merupaka salah satu metode statistika deskriptif yang menyajikan plot posisi relatif $n$ objek pengamatan dengan $p$ variabel secara simultan dalam satu grafik dua dimensi. Informasi yang dapat diperoleh dari analisis biplot antara lain kedekatan antar objek, keragaman peubah, dan korelasi antar peubah. .

\section{Analisis Diskriminan}

Analisis diskriminan bertujuan untuk mengklasifikasikan suatu observasi ke dalam kelompok yang saling bebas berdasarkan sejumlah variabel penjelas. Asumsi yang harus dipenuhi dalam analisis diskriminan adalah data berdistribusi multivariate normal, matriks varians-covarians variabel penjelas pada kedua kelompok harus sama, dan uji nilai perbedaan rata- rata antar kelompok.

\subsection{Uji Multivariate Normal}

Pengujian hipotesa asumsi multivariate normal adalah sebagai berikut:

\section{$\mathrm{H}_{0}$ : Data berdistribusi multivariate normal \\ $\mathrm{H}_{1}$ : Data tidak berdistribusi multivariate normal}

Pengujian multivariate normal yaitu dengan membandingkan $d_{f}^{2}$ dengan nilai tabel Chi-Square $\chi_{p \mid \alpha \times}^{2}$.

$d_{j}^{2}=\left(x_{j}-\bar{x}\right)^{1} s^{-1}\left(x_{j}-\bar{x}\right), \mathrm{j}=1,2, \ldots, \mathrm{n}$

Dimana:

$\mathrm{N}$ : banyaknya pengamatan

$x_{j} \quad$ : Objek pengamatan ke-j

$s^{-1} \quad$ :Invers Matrik kovarians berukuran $p x p$

\subsection{Uji Kesamaan Matrik Ragam- Peragam}

Untuk menguji kesamaan matrik ragam peragam antar kelompok dapat digunakan hipotesa sebagai berikut:

$H_{0}: \Sigma_{1}=\Sigma_{2}=\cdots=\Sigma_{k}$

$H_{1}$ : minimal satu $\Sigma_{i} \neq \Sigma_{j}$

Statistik uji yang digunakan adalah Box's $M$ yaitu:

$$
\begin{gathered}
-2 \operatorname{Ln} \lambda^{*}=\left.(n-k) L n\right|^{W} /(n-k)\left|-\sum_{i=1}^{k}\left(n_{i}-1\right) L n\right| s_{j} \mid \\
\lambda^{*}=\frac{\prod_{j=:}^{k}\left|s_{j}\right|^{\left(n_{j}-1\right) / 2}}{\left|w^{*} /(n-k)\right|^{(n-k)_{/ 2}}}
\end{gathered}
$$

Dimana:

$$
\begin{array}{ll}
k & : \text { banyaknya kelompok } \\
W_{/(x-k)} & : \text { Matrik ragam-peragam } \\
& \text { dalam kelompok gabungan } \\
s_{j} & \text { :Matrik ragam- peragan } \\
& \text { kelompok ke- } j
\end{array}
$$

Jika $\quad\left(-2 \operatorname{Ln} \lambda \lambda^{*}\right) f_{b} \in F_{v_{g} v_{\mathrm{v}} \alpha} \quad$ maka keputusan tolak $H_{0}$ yang berarti bahwa antar kelompok memiliki matrik ragamperagan yang sama, dengan $\alpha$ adalah tingkat signifikansi dan $\mathrm{v}_{1}$ dan $\mathrm{v}_{2}$ adalah derajat bebas

\subsection{Uji Vektor Nilai Rataan}

Pengujian terhadap vektor nilai rataan antar kelompok dikakukan dengan hipotesa:

$H_{0}: \mu_{1}=\mu_{2}=\cdots=\mu_{k}$

$H_{1}$ : minimal satu $\mu_{i} \neq \mu_{i}$

Statistik uji yang digunakan adalah statistik $V$-Bartlett yang menyebar mengikuti sebaran Chi-Square $x_{p(k-1)(1-\alpha)}^{2}$. 


\section{HASIL DAN PEMBAHASAN}

\section{Analisis Deskriptif}

Nilai IPM di Provinsi Sulawesi Utara pada tahun 2017 berkisar antara 64,05 sampai dengan 78,05. Berdasarkan kriteria BPS dalam publikasi Indek Pembangunan Manusia Tahun 2017 tentang status pembangunan manusia yang terbagi menjadi 4 kelompok, IPM Provinsi Sulawesi Utara pada tahun 2017 menduduki ketegori sedang dan tinggi.

Tabel 2. Kategori IPM Kabupaten/ Kota di Provinsi Sulawesi Utara Tahun 2017

\begin{tabular}{lc}
\hline \multicolumn{1}{c}{ Kategori IPM } & Jumlah Kabupaten/ Kota \\
\hline Sangat tinggi $(\geq 80)$ & - \\
Tinggi $(70 \leq$ IPM $<80)$ & 7 \\
Sedang $(60 \leq \mathrm{IPM}<70)$ & 8 \\
Rendah $($ IPM $<60)$ & - \\
\hline
\end{tabular}

Kota Manado merupakan wilayah dengan IPM tertinggi, sedangkan wilayah dengan nilai IPM terendah adalah Kabupaten Bolaang Mongondow Selatan.

Pada tahun 2017, persentase kemiskinan di Provinsi Sulawesi Utara adalah sebesar 8,10. Persentase kemiskinan terendah terdapat di Kota Manado, yaitu sebesar 5,46, sedangkan persentase kemiskinan terbesar berada di Kabupaten Bolaang Mongondow Selatan, yaitu sebesar 14,16.

Pertumbuhan ekonomi Provinsi Sulawesi Utara pada Tahun 2017 adalah sebesar 6,32. Kabupaten dengan pertumbuhan ekonomi di bawah rata-rata pertumbuhan ekonomi provinsi ada sebanyak 7 kabupaten. Kabupaten dengan pertumbuhan ekonomi terendah adalah Kabupaten Kepulauan Talaud yaitu sebesar 5,11, sedangkan wilayah dengan pertumbuhan ekonomi tertinggi adalah Kota Tomohon dengan pertumbuhan ekonomi sebesar 8,85.

Tingkat Pengangguran Terbuka (TPT) Provinsi Sulawesi Utara pada Bulan Agustus 2017 adalah sebesar 7,18.
Tingkat pengangguran terbuka terbesar berada di Kota Bitung, yaitu sebesar 9,85, sedangkan kabupaten dengan tingkat pengangguran terbuka terendah adalah Kabupaten Kepulauan Sitaro

\section{Analisis Biplot}

Berdasarkan grafik biplot pada gambar 1, keragaman yang dapat dijelaskan oleh dimensi 1 sebesar 76,0 persen dan dimensi 2 sebesar 14,9 persen, sehingga secara keseluruhan keragaman yang dapat dijelaskan oleh kedua dimensi adalah sebesar 90,9 persen. Hal ini berarti bahwa informasi yang dapat dijelaskan oleh peta biplot menggunakan dua komponen utama tersebut adalah sebesar 90,9 persen.

Kabupaten/ kota yang berada pada posisi yang berdekatan dapat dikatakan memiliki karakteristik variabel sosial ekonomi yang cukup dekat. Pada grafik diatas terlihat bahwa untuk IPM, Kabupaten Minahasa Utara dan Kota Bitung memiliki posisi yang cukup dekat. Hal ini berarti Kabupaten Minahasa Utara dan Kota Bitung memiliki kesamaan karakteristik untuk variabel IPM. 


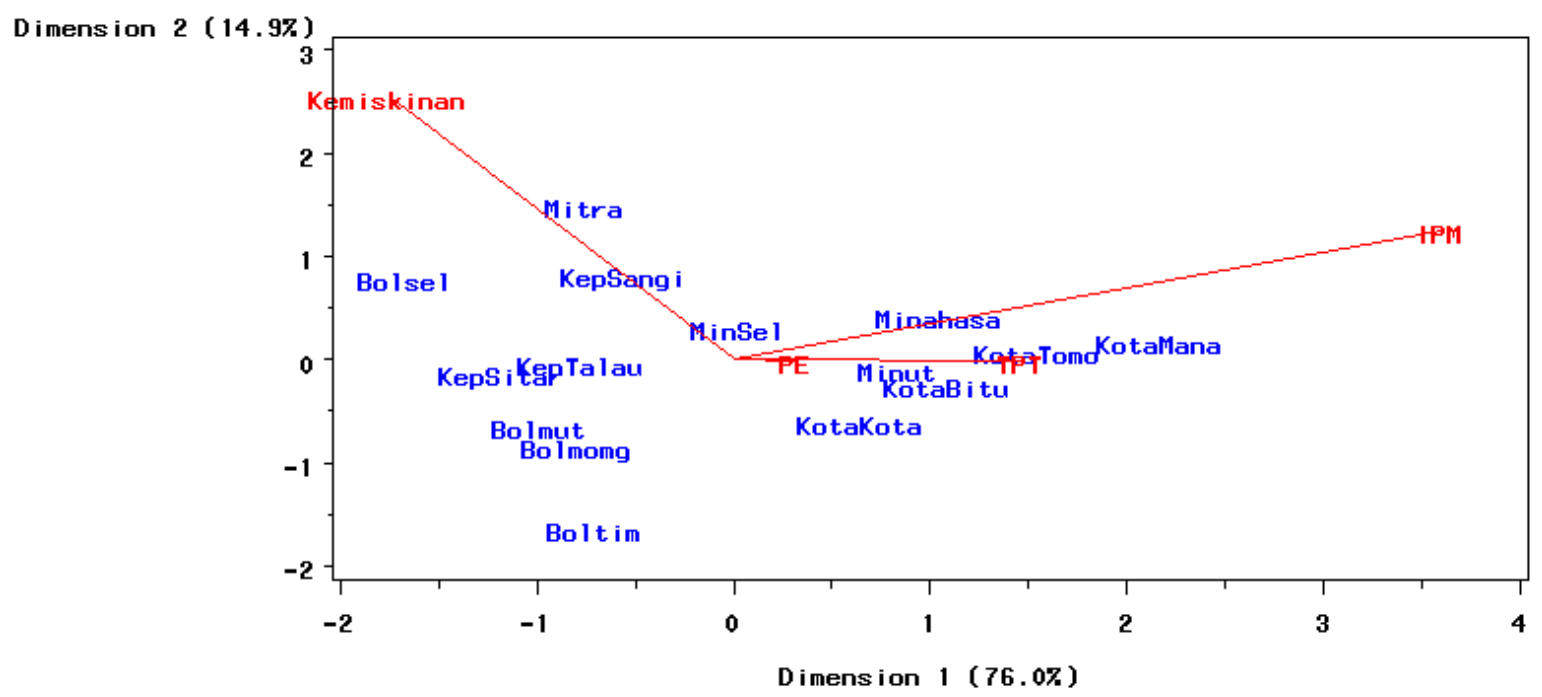

\section{Gambar 1. Hasil Biplot Variabel Sosial Ekonomi Kabupaten/Kota di Provinsi Sulawesi Utara Tahun 2017}

Informasi keragaman variabel dapat dilihat dari panjang vektor yang terbentuk. IPM memiliki panjang vektor yang terpanjang dibandingkan dengan panjang vektor variabel lainnya. Hal ini berarti bahwa keragaman data IPM di kabupaten/ kota relatif tinggi. Panjang vektor untuk variabel pertumbuhan ekonomi memiliki panjang vektor yang terpendek, berarti keragaman data pertumbuhan ekonomi kabupaten/ kota di Provinsi Sulawesi Utara pada tahun 2017 relatif kecil.

Variabel IPM, pertumbuhan ekonomi, dan tingkat pengangguran terbuka memiliki korelasi positif, sedangkan variabel persentase kemiskinan memiliki korelasi negatif dengan ketiga variabel lainnya. Hal ini dapat diketahui dari sudut antar vektor variabel yang membentuk sudut lancip. Sudut antar dua variabel yang semakin kecil menunjukan bahwa korelasi kedua variabel tersebut semakin tinggi.
Grafik biplot memberikan gambaran kedekatan antar kabupaten/ kota serta kedekatan kabupaten/ kota dengan variabel sehingga kabupaten/kota di Provinsi Sulawesi Utara tahun 2017 dapat dikelompokan sebagai berikut:

1. Kelompok Pertama : Kabupaten Bolaang Mongondow, Kabupaten Kepulauan Sangihe, Kabupaten Kepulauan Talaud, Kabupaten Minahasa Selatan, Kabupaten Bolaang Mongondow Utara, Kabupaten Kepulauan Sitaro, Kabupaten Minahasa Tenggara, Kabupaten Bolaang Mongondow Selatan, dan Kabupaten Bolaang Mongondow Timur.

2. Kelompok Kedua : Kota Manado, Kota Tomohon, Kota Bitung, Kota Kotamobagu, Kabupaten Minahasa, dan Kabupaten Minahasa Utara 


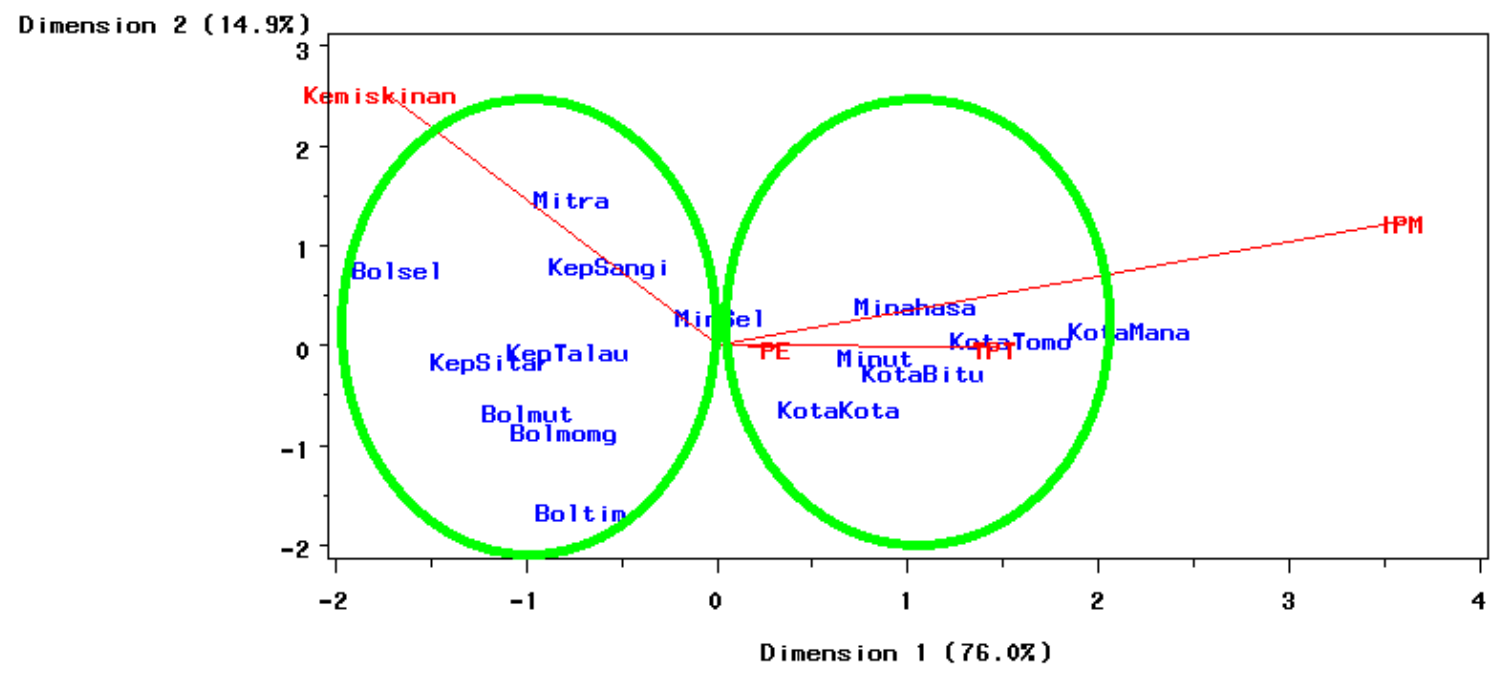

\section{Gambar 2. Hasil Pengelompokan Kabupaten/ Kota di Sulawesi Utara Tahun 2017}

Kelompok pertama terdiri dari 9 (Sembilan) kabupaten di Provinsi Sulawesi Utara. Wilayah ini merupakan kabupaten dengan karakteristik IPM, pertumbuhan ekonomi, dan tingkat pengangguran terbuka yang relatif rendah serta persentase kemiskinan yang relatif tinggi.

Kelompok pertama memiliki tingkat pertumbuhan ekonomi yang relatif rendah dengan kemiskinan relatif tinggi namun tingkat pengangguran di wilayah ini tergolong relatif rendah. Hal ini mengindikasikan bahwa wilayah tersebut memiliki kecenderungan wilayah dengan karakteristik padat karya.

Kelompok kedua terdiri dari seluruh kota di Provinsi Sulawesi dan dua kabupaten. Kedua kabupaten yang menjadi wilayah kelompok kedua merupakan kabupaten yang terletak berbatasan dengan wilayah-wilayah kota. Kabupaten Minahasa Utara dan Kabupaten Minahasa merupakan wilayah yang diapit oleh dua kota yang berdekatan. Kabupaten Minahasa terletak berdekatan dengan Kota Manado dan Kota Tomohon, sedangkan Kabupaten Minahasa Utara terletak diantara Kota Manado dan Kota Bitung. Hal ini berdampak pada pembangunan dan karakteristik wilayah di Kabupaten Minahasa dan Kabupaten Minahasa Utara.

Karakteristik kelompok yang terbentuk untuk kelompok kedua adalah wilayah dengan nilai IPM, pertumbuhan ekonomi, dan tingkat pengangguran terbuka yang relatif tinggi, sedangkan persentase kemiskinan relatif rendah. Kelompok ini merupakan wilayah dengan kondisi pembangunan daerah yang cukup maju dibandingkan dengan kelompok pertama.

Keberhasilan pembangunan daerah pada kelompok kedua terkait pertumbuhan ekonomi yang relatif tinggi, tidak diikuti dengan keberhasilan penanggulangan tingkat pengangguran. Tingkat pengangguran di wilayah kelompok kedua merupakan tingkat pengangguran yang relatif tinggi. Hal ini 
mengindikasikan bahwa wilayah tersebut cenderung memiliki karakteristik padat modal.

\section{Uji Diskriminan}

\section{a. Uji Multivariate Normal}

$\mathrm{H}_{0}$ : Data berdistribusi multivariate Normal
$\mathrm{H}_{1}$ : Data tidak berdistribusi multivariate normal

Hasil pengujian multivariate normal dengan metode Mardia yaitu dengan Mardia skewness dan kurtosis adalah sebagai berikut:

Tabel 3 . Hasil Pengujian Multivariate Normal

\begin{tabular}{lrrr}
\hline \multicolumn{1}{c}{ Metode Mardia } & \multicolumn{1}{c}{$\mathrm{b}$} & $\mathrm{z}$ & p-value \\
\hline $\begin{array}{l}\text { Multivariate } \\
\text { skewness }\end{array}$ & 5,25 & 17,03 & 0,65 \\
multivariate kurtosis & 20,62 & $-0,94$ & 0,35 \\
\hline
\end{tabular}

Hasil pengujian dengan multivariate skewness dan multivariate kurtosis menunjukan bahwa nilai $p$-value untuk multivariate skewness adalah 0,65 dan $p$ value untuk multivariate kurtosis adalah 0,35 dimana $p$-value $>\alpha(0,05)$ sehingga dapat disimpulkan bahwa data pengamatan yang digunakan dalam penelitian ini berdistribusi multivariate normal.

\section{b. Uji Kesamaan Matrik ragam peragam}

Tahap pengujian selanjutnya adalah uji asumsi kesamaan matrik ragamperagam antara kelompok pertama dan kedua,hasil pengujian adalah sebagai berikut:

\section{Tabel 4. Hasil pengujian Kesamaan Matrik Ragam-Peragam}

\begin{tabular}{clr}
\hline Box's $M$ & & 0,051 \\
\hline \multirow{4}{*}{ F } & Approx. & 0,47 \\
& $d f 1$ & 1 \\
& $d f 2$ & 438,72 \\
& Sig. & 0,83 \\
\hline
\end{tabular}

Hasil pengujian kesamaan matrik ragam peragam menunjukan bahwa dengan tingkat kepercayaan $95 \%$, kelompok pertama dan kelompok kedua memiliki matrik ragam-peragam yang sama ditunjukan dengan nilai signifikansi 0,83 lebih besar dari 0,05. Hal ini berarti asumsi kedua kelompok memiliki matrik ragam-peragam yang sama terpenuhi.

\section{c. Uji Perbedaan Rata-Rata antar Kelompok}

Asumsi distribusi multivariate normal dan kesamaan matrik ragam-peragam telah dipenuhi, selanjutnya dilakukan uji perbedaan rata-rata antar kelompok. 
Hasil pengujian perbedaan rata-rata antar kelompok dapat ditunjukan pada tabel 5. sebagai berikut:

1. Variabel persentase kemiskinan, IPM, dan TPT memiliki nilai signifikansi $<0,05$ yang berarti bahwa ada perbedaan rata-rata persentase kemiskinan, IPM, dan
TPT.antar kelompok.

2. Asumsi perbedaan rata-rata antar kelompok pada penelitian ini terpenuhi karena lebih dari 50 persen dari total peubah yang dianalisis telah signifikan berbeda antar kelompok.

Tabel 5. Hasil Uji Perbedaan Rata-Rata antar Kelompok

\begin{tabular}{lccccc}
\hline \multicolumn{1}{c}{ Variabel } & Wilks' Lambda & F & df1 & df2 & Sig. \\
\hline \multicolumn{1}{c}{$(1)$} & $(2)$ & $(3)$ & $(4)$ & $(5)$ & $(6)$ \\
\hline Persentase Kemiskinan & 0,550 & 10,652 & 1 & 13 & 0,006 \\
Pertumbuhan Ekonomi & 0,822 & 2,819 & 1 & 13 & 0,117 \\
IPM & 0,247 & 39,586 & 1 & 13 & 0,000 \\
TPT & 0,497 & 13,147 & 1 & 13 & 0,003 \\
\hline
\end{tabular}

Hasil crosstabulasi antara model awal dengan pengklasifikasian model diskriminan untuk mengukur ketepatan klasifikasi ditunjukan pada tabel 6. Pada tabel 6 terlihat bahwa ketepatan klasifikasi yang diperoleh cukup tinggi, yaitu sebesar 100 persen.
Hal ini dapat mengindikasikan bahwa ketepatan pengelompokan kabupaten. Kota di Provinsi Sulawesi Utara Tahun 2017 berdasarkan karakteristik sosial ekonomi menjadi 2 kelompok wilayah memiliki ketepatan yang baik.

Tabel 6. Hasil Klasifikasi dengan Metode Diskriminan

\begin{tabular}{llrrrr}
\hline \multirow{2}{*}{ Cluster Number of Case } & \multicolumn{3}{c}{$\begin{array}{c}\text { Predicted Group } \\
\text { Membership }\end{array}$} & \multirow{2}{*}{ Total } \\
\cline { 3 - 5 } & & 1 & 2 & \\
\cline { 3 - 5 } Original & \multirow{3}{*}{ Count } & 1 & 9 & 0 & 9 \\
\cline { 2 - 5 } & 2 & 0 & 6 & 6 \\
\cline { 2 - 5 } & \multirow{2}{*}{$\%$} & 1 & 100,0 & 0,0 & 100,0 \\
& 2 & 0,0 & 100,0 & 100,0 \\
\hline
\end{tabular}

\section{SIMPULAN}

Pengelompokan kabupaten/ kota di Provinsi Sulawesi Utara pada Tahun 2017 berdasarkan karakteristik sosial ekonomi dengan menggunakan analisis biplot menghasilkan dua kelompok wilayah yang berbeda.

Kelompok pertama yang terbentuk terdiri dari seluruh kabupaten di Provinsi Sulawesi Utara kecuali kabupaten 
Minahasa dan Minahasa Utara. persentase kemiskinan yang cenderung Karakteristik wilayah pada kelompok pertama adalah wilayah dengan kecenderungan nilai IPM, pertumbuhan ekonomi, dan tingkat pengangguran terbuka yang relatif rendah serta tinggi.

Kelompok kedua merupakan wilayah dengan karakteristik daerah perkotaan dan daerah yang berbatasan langsung dengan perkotaan dengan kecenderungan daerah yang padat modal.

\section{DAFTAR PUSTAKA}

Badan Pusat Statistik (2018). Data dan Informasi Kemiskinan Kabupaten/ Kota Tahun 2017. Jakarta: Badan Pusat Statistik.

Badan Pusat Statistik (2018). Indeks Pembangunan Manusia 2017. Jakarta: Badan Pusat Statistik.

Badan Pusat Statistik Provinsi Sulawesi Utara (2018). Provinsi Sulawesi Utara Dalam Angka 2018. Manado: BPS Provinsi Sulawesi Utara.

Badan Pusat Statistik Provinsi Sulawesi Utara (2018). Keadaan Ketenagakerjaan Provinsi Sulawesi Utara 2017. Manado: BPS Provinsi Sulawesi Utara.

Badan Pusat Statistik Provinsi Sulawesi Utara (2018). Profil Ketenagakerjaan Provinsi Sulawesi Utara Tahun 2017. Manado: BPS Provinsi Sulawesi Utara.

Johnson, Ricard, and Dean (2007). Applied Multivariate Statistical Analysis. United State of America: Pearson Education. Inc.

Purwandari, T \& Hidayat, Y. (2016). Pengelompokan Kabupaten dan Kota di Jawa Barat Menggunakan Principal Component Analysis BIPLOT, Dalam prosiding Seminar Nasional Pendidikan Matematika (pp. 1-9).

Putri, M.M \& Fithriasari, K. (2015). Pengelompokan Kabupaten/ Kota di Jawa Timur Berdasarkan Indikator Kesehatan Masyarakat Menggunakan Metode Kohonen SOM dan K-Means. Jurnal Sains dan Seni ITS 4, 13-18.

Rukini (2017, Maret). Analisis Perubahan Kelompok Berdasarkan Indikator Kesejahteraan Rakyat Tahun 2010-2015 di Provinsi Jawa Tengah, Dalam prosiding Konferensi Nasional Penelitian Matematika dan Pembelajarannya II (KNPMP II) (pp. 210222).Universitas Muhammadiyah Surakarta.

Soemartini \& Supartini (2017, Maret). Analisis K-Mean Cluster untuk Pengelompokan Kabupaten/ Kota di Jawa Barat Berdasarkan Indikator Masyarakat, Dalam prosiding Konferensi Nasional Penelitian Matematika dan Pembelajarannya II (KNPMP II) (pp. 144-154).Universitas Muhammadiyah Surakarta. 